\title{
Looking forward into the next 25 years: the 25th anniversary issue of the Journal of Computer-Aided Molecular Design
}

\author{
Terry Richard Stouch
}

Received: 11 January 2012/ Accepted: 12 January 2012/Published online: 17 January 2012

(C) Springer Science+Business Media B.V. 2012

This issue is the first of the 26th year of the Journal of Computer-Aided Molecular Design (JCAMD). With this issue we commemorate JCAMD's 25th anniversary, the last 25 years, and even more so we look toward the future, forward into the next 25 years.

In this issue, you will find a diverse set of Perspectives from 32 prominent thought leaders including our founders, editorial board members, past editors, frequent reviewers, and frequent authors. They were given free rein to express themselves with whatever length, topic, and tone they desired. Our only request was that they consider "what will, can, or must happen in the next 25 years [to our field]". In that we cannot truly consider what will happen without understanding the past and present, several of the authors also provide us with insight into our history and many hold a mirror to the present.

The result is an intriguing set of papers of many topics, lengths, and tones: serious, funny, entertaining, thought provoking, critical, laudatory, despairing, hopeful, prophetic, and even one science fiction (future fact?) story. They are too diverse to summarize here and so diverse that the editors found it hard to classify and order them. Consequently, they appear simply in alphabetical order with one exception, that of Garland Marshall, a distinguished founder both of JCAMD and Perspectives in Drug
Discovery and Design (PD3) (which was merged into $J C A M D$ in 2001). Indeed, Professor Marshall is a founder of the field of computer-aided molecular design, itself.

In fact, without the vision of our founders, our unique journal (the only one dedicated solely to the field of CAMD) would not have been available to the thousands of authors who have published here in the last 25 years. JCAMD was founded in 1987 by Garland Marshall, HansDieter Holtje, and J. D. Vinter. PD3 was founded by Paul Anderson, George Kenyon and Garland Marshall. Consequently, we would like to dedicate this issue to those ultimately responsible, our founders.

In honor of this occasion, Spring Publishing has generously granted free online open-access for 3 months after publication. Please enjoy. Comments are welcome as always as a submission to "letters to the editor".

Terry Stouch, Senior Editor-in-Chief, Journal of Computer-Aided Molecular Design.

Yvonne Martin, Editor-in-Chief, Perspectives in Drug Discovery and Design.

Federico Gago, Editor-in-Chief, Journal of ComputerAided Molecular Design.

Andrew Leach, Editor-in-Chief, Journal of ComputerAided Molecular Design.
T. R. Stouch $(\square)$

Science For Solutions, LLC, 6211 Kaitlyn Ct,

West Windsor, NJ 08550, USA

e-mail: tstouch@gmail.com 